Research Article

\title{
An Integrated Method for Fire Risk Assessment in Residential Buildings
}

\author{
Hongfu Mi ${ }^{D},{ }^{1}$ Yaling Liu, ${ }^{1}$ Wenhe Wang, ${ }^{1}$ and Guoqing Xiao ${ }^{2}$ \\ ${ }^{1}$ College of Safety Engineering, Chongqing University of Science and Technology, Chongqing 401331, China \\ ${ }^{2}$ College of Chemistry and Chemical Engineering, Southwest Petroleum University, Chengdu 610500, China
}

Correspondence should be addressed to Hongfu Mi; mimihh5@163.com

Received 12 May 2020; Revised 10 August 2020; Accepted 17 August 2020; Published 26 August 2020

Guest Editor: Esam Hafez Abdelhameed

Copyright (c) 2020 Hongfu Mi et al. This is an open access article distributed under the Creative Commons Attribution License, which permits unrestricted use, distribution, and reproduction in any medium, provided the original work is properly cited.

Building fires are characterized by high uncertainty, so their fire risk assessment is a very challenging task. Many indexes and parameters related to building fires are ambiguous and uncertain; as a result, a flexible and robust method is needed to process quantitative or qualitative data and update existing information when new data are available. This paper presents a novel model to deal with the uncertainty of the residential building fire risk and systematically optimize its performance effectiveness. The model includes fuzzy theory, evidence reasoning theory, and expected utility methods. Fuzzy analysis hierarchy process is applied to analyze the residential building fire risk index system and determine the weights of the risk indexes, while the evidence reasoning operator is used to synthesize them. Three buildings were selected as a case study to illustrate the proposed fire risk model. The results show that the fire risk level of three buildings corresponds to "moderate" or below which is consistent with the previous study. These results also truly reflect the actual situation of fire safety in these residential buildings. The application of this model provides a powerful mathematical framework for cooperative modeling of the fire risk assessment system and allows data to be analyzed step by step in a systematic manner. It is expected that the proposed model could provide managers and researchers with flexible and transparent tools to effectively reduce the fire risk in the system.

\section{Introduction}

With the acceleration of industrialization, urbanization, and marketization in China, building construction industry has developed rapidly. Particularly, the structure and function of buildings are becoming more complex, and various new technologies and techniques are emerging constantly, which have led to the increasingly severe situation of building fires. According to the statistics provided by the Ministry of Public Security in 2013, a total of 388,821 fires were recorded in China, in which $52 \%(202,299)$ of fires occurred in buildings, resulting in 3410 civilian deaths or injuries and 3760 million Chinese yuan (CNY) direct property losses. Nowadays, building fire is considered to be an enormous threat to people's life and production in China, and a growing concern is how to take appropriate measures to reduce the fire risk, minimize the damage and loss caused by fire in buildings, and guarantee building fire safety. Therefore, it is urgent to establish a suitable fire risk assessment model, and it provides information through quantitative or qualitative analysis results to make decisions on whether to take steps to reduce the risk $[1,2]$.

There are mainly four conventional types of fire risk analysis methods: checklist, description, index, and probability method [3]. However, most of these approaches have prescriptive drawbacks which make them difficult to quantitative fire risk analysis due to the inability to deal with the uncertainties associated with the fire risk factors of the system. With the improvement of performance-based fireprotection design, some fire risk analysis models and corresponding software have emerged, such as FiRECAM ${ }^{\mathrm{TM}}$ (Fire Risk Evaluation and Cost Assessment Model) [4, 5], FIERAsystem (Fire Evaluation and Risk Assessment system) [6], CESARE-RISK (Centre for Environment Safety and Risk Engineering, RISK) [7, 8], and Crisp II (Computation of Risk Indices by Simulation Procedures) [9]. However, these models should depend on some strict constraints, such as a 
large number of input data, specific fire scenarios, and the large amount of calculations. Consequently, researchers are concentrating on developing flexible fire risk analysis tools based on systematic safety theory. For example, Ibrahim et al. presented a fire risk method based on the analytical hierarchy method (AHP) for heritage buildings [10]. Lo developed a fire risk ranking system for existing buildings using the fuzzy set approach [11]. Liu et al. built a fire risk analysis system for commercial buildings by using the structure entropy weight method [12]. Xin and Huang proposed scenario cluster methods in the process of the fire risk analysis model for residential buildings [2]. Briefly speaking, these methods reveal two main challenges in an uncertain environment associated with the fire risk factors of the system. The first challenge faced by these methods is the lack of the ability to process a variety of data suitable for fire risk reasoning mechanisms, and the second is the lack of the ability to analyze the interdependence of risk factors. In this paper, a fire risk analysis model integrated fuzzy theory, and evidential reasoning (ER) theory is presented for residential buildings. Compared with the traditional fuzzy reasoning approach, ER has the advantage of avoiding losing useful information; therefore, it can be applied to model complex systems. The framework of this model is organised as follows. Section 2 illustrates the methodology of the research. Section 3 presents a case study to verify the feasibility of the methodology. Sections 4 and 5 discuss the empirical results and conclusions.

\section{Methodology}

Quantitative risk assessment (QRA) techniques are usually used for assessing uncertainties in building fires. However, due to the lack of fire accident statistics, an effective solution is to integrate expert judgments into the QRA process. QRA consists of four main procedures: hazard identification, occurrence probability calculation, consequence severity assessment, and risk quantification $[13,14]$. In order to process the complex system structure and promote a flexible implementation method, different decision-making techniques can be used, such as fuzzy analytic hierarchy process, fuzzy set theory, and evidence reasoning method. Due to the fact that fuzzy logic could provide a flexibility way to represent the vague information resulting from the lack of data or knowledge. Therefore, the fuzzy set theory has a wide application in different fields such as reliability engineering, system safety, and risk assessment [15].

The proposed framework, shown in Figure 1, allows step-by-step analysis of the utility tunnel fire risk in a transparent way, as described as follows:

(1) Identifying fire risk factors and establishing the hierarchical structure of the index system

(2) Using fuzzy analytic hierarchy process (FAHP) to calculate the weights of indexes

(3) Applying the belief degree structure based on the fuzzy set theory to measure the fire risk

(4) Aggregating the result of the fire risk using the evidence reasoning (ER) algorithm
(5) Using the expected utility method to obtain a clear result of the fire risk

(6) Sensitivity analysis

2.1. Identifying Fire Risk Factors and Establishing the Hierarchical Structure of the Index System. In order to make better decisions on fire control protection and emergency evacuation measures, a structured and systematic approach is needed. It is better to describe the fire risk problem in a hierarchical structure so that decision makers could have a thorough understanding of the system, especially when it is a complex system with multilevel structural indexes.

According to NFPA550 Guidelines, to achieve fire safety, reducing the fire risk mainly starts from two aspects: one is to prevent the occurrence of fire, and the other is to control the impact of fire [16]. In this paper, fire risk factors of these two aspects are, respectively, defined as disaster-causing factors and loss-controlling factors. Disaster-causing factors may cause the fire risk to be transformed into disaster before fire occurs, while loss control factors signified various fire protection and management measures to control the development process of fire and mainly involved four aspects: passive measures, active measures, fire management, and fire brigade fighting.

Based on the characteristics of residential building fire and the literature review $[6,17-20]$, the factors influencing the risk of building fires are analyzed from the two aspects of disaster-causing factors and loss-controlling factors. A general hierarchical structure (presented in Figure 2) is finally established after theoretical preparation, the initial construction of the index system, the optimization of the index system, and the determination of the index system.

2.2. Fuzzy Analytic Hierarchy Process (FAHP). The traditional analytic hierarchy process (AHP) constructs the judgment matrix by comparing the two factors with the 1-9 scale method. However, due to the subjectivity of human judgment, different people will get different conclusions. Using the triangular fuzzy number to scale the two-pair comparison of factors can consider the uncertainty of experts in analysis and judgment, which give the range of expert's judgment in the form of intervals to reduce subjectivity. In 1996, Chang [21] applied triangular fuzzy numbers to construct judgment matrices and combined with the extent analysis method to calculate the weights of each index in the hierarchical structure. Finally, the traditional AHP is transformed into the FAHP in the fuzzy environment, which can provide more practical results [22].

2.2.1. Triangular Fuzzy Number. Suppose the triangular fuzzy number is $M$, and its membership function $\mu_{M}: R \longrightarrow[0,1]$ is equal to 


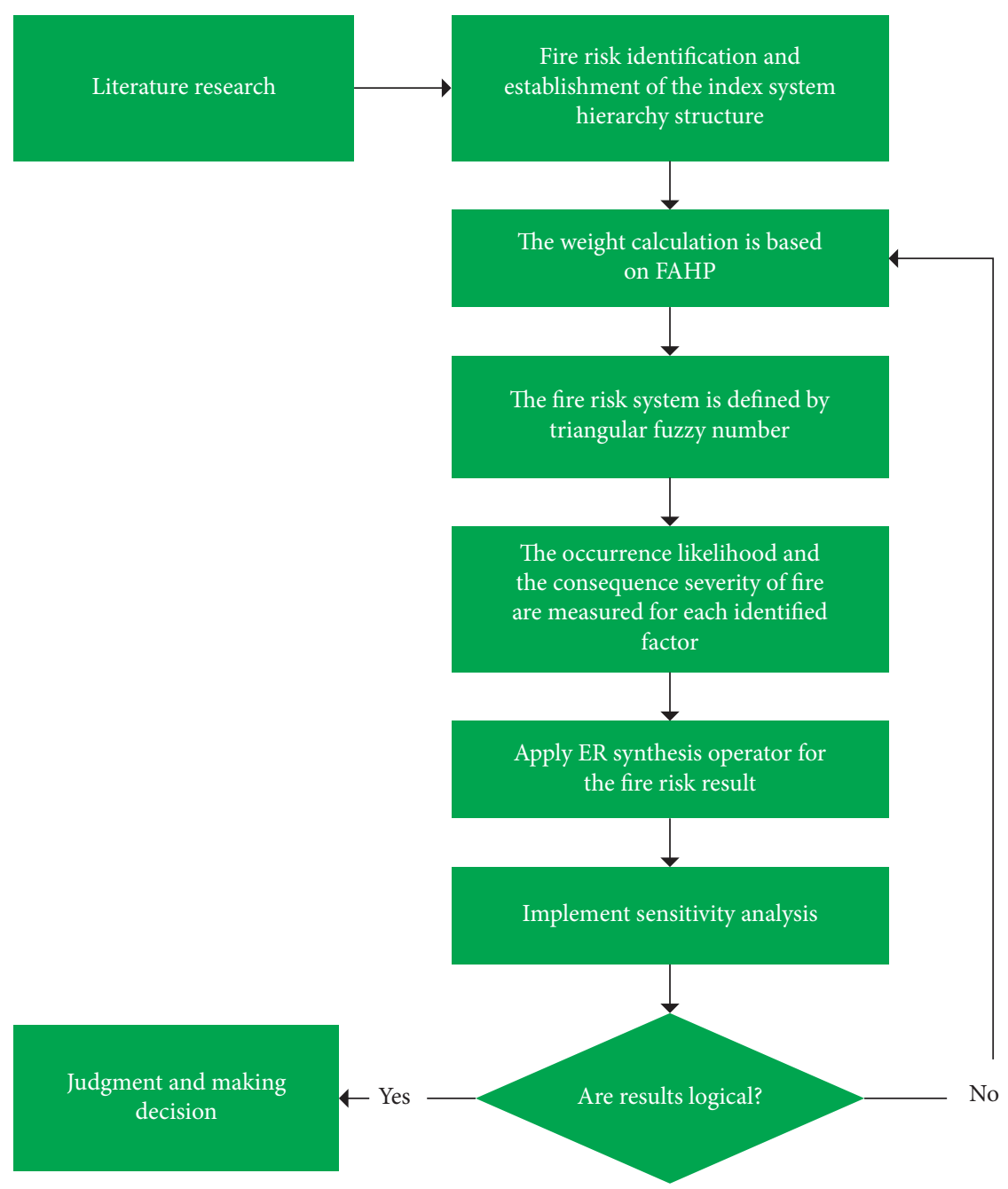

FIgURE 1: The procedure for fire risk assessment in residential buildings.

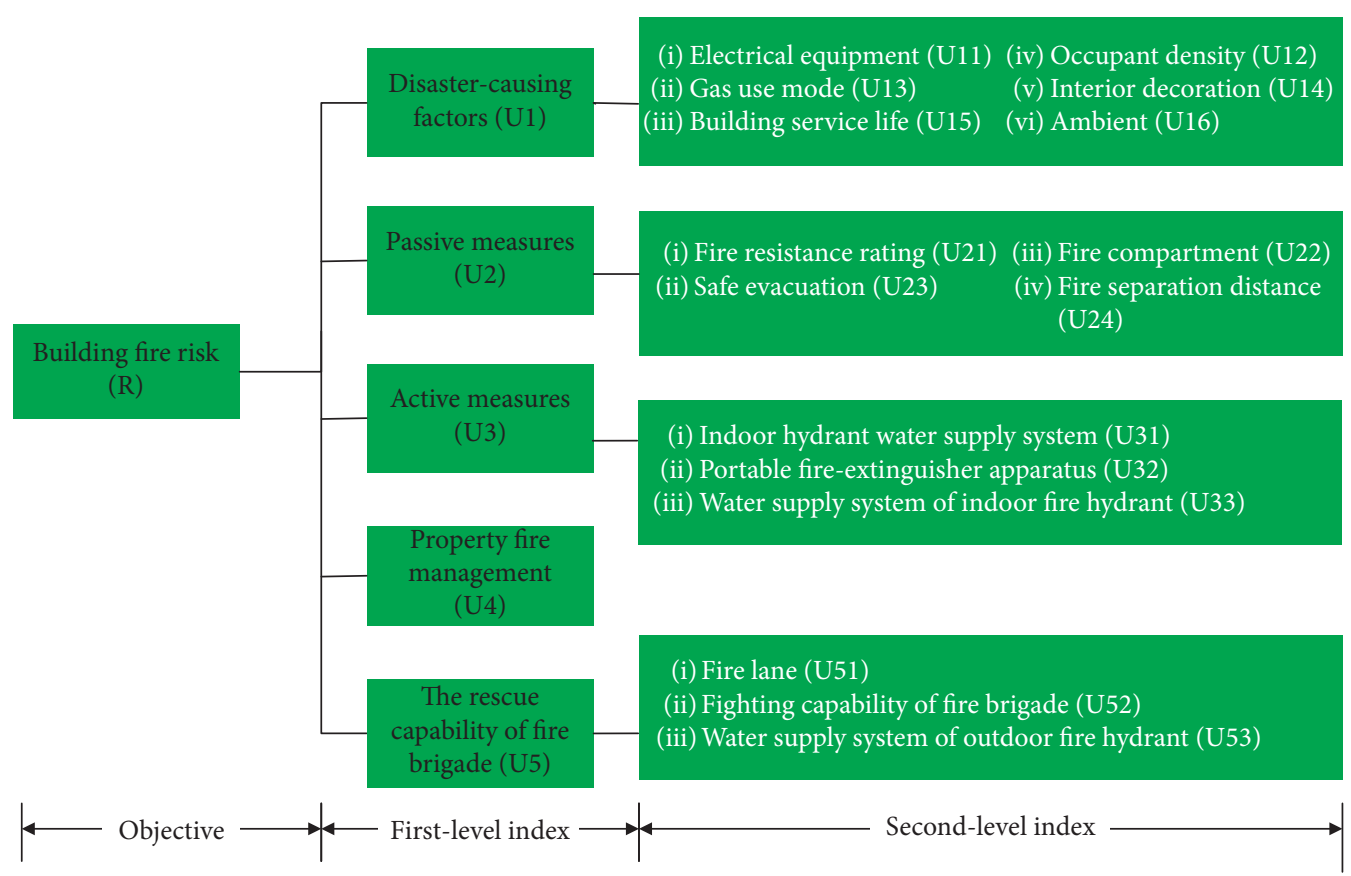

FIgURE 2: The hierarchical structure for the residential building fire risk model. 


$$
\mu_{M}(x)= \begin{cases}\frac{x-l}{m-l}, & l \leq x \leq m, \\ \frac{x-u}{m-u}, & m \leq x \leq u \\ 0, & \text { otherwise. }\end{cases}
$$

Herein, $l \leq m \leq u, l$ and $u$ represent the lower and upper boundary value of triangular fuzzy number $M$, respectively, and $m$ represents the median value of triangular fuzzy number $M$. Generally, triangular fuzzy number $M$ can be abbreviated as $(l, x, m)$. Let $M_{1}=\left(l_{1}, x_{1}, m_{1}\right)$ and $M_{2}=\left(l_{2}, x_{2}, m_{2}\right)$ be triangular fuzzy numbers; then, the possibility degree of $M_{1} \geq M_{2}$ is defined as follows:

$$
V\left(M_{1} \geq M_{2}\right)= \begin{cases}1, & m_{1} \geq m_{2}, \\ \frac{l_{2}-u_{1}}{\left(m_{1}-u_{1}\right)-\left(m_{2}-l_{2}\right)}, & m_{1}<m_{2}, l_{2} \leq u_{1}, \\ 0, & \text { otherwise. }\end{cases}
$$

2.2.2. Fuzzy Synthetic Extent. Consider $X=\left\{x_{1}, x_{2}, \ldots, x_{n}\right\}$ as a set of analytic objects and $U=\left\{u_{1}, u_{2}, \ldots, u_{n}\right\}$ as a target set; we can get the extent value of the $i$-th object satisfying the $j$-th goal, in which the sign is $M_{E_{i}}^{j}$. Then, the value of synthetic extent of the $i$-th object is defined as $[21,23]$

$$
S_{i}=\sum_{j=1}^{m} M_{E_{i}}^{j}\left(\sum_{i=1}^{n} \sum_{j=1}^{m} M_{E_{i}}^{j}\right)^{-1} .
$$

2.2.3. The Procedure of the FAHP. In the evaluation of the fire risk, the determination of the weight of each fire risk factor is particularly important. The weight represents the relative importance of each factor in the overall evaluation. Only when the weight of each factor is obtained, the fire risk assessment can be carried out. The steps of determining the weight by the FAHP method are as follows:

(1) According to the objective of fire risk assessment, the hierarchical system structure is established, which is composed of fire risk factors.

(2) The judgment matrix is constructed by triangular fuzzy numbers (according to Table 1) through a pairwise comparison of the index system by experts [24, 25].

(3) According to equation (3), the value $S_{i}$ of synthetic extent $S_{i}$ of each factor is obtained.
(4) The possibility degree $d^{\prime}\left(A_{i}\right)$ is calculated such that factor $A_{i}$ is more important than others:

$$
d^{\prime}\left(A_{i}\right)=\underbrace{\min }_{j=1,2, \ldots, n, j \neq i} V\left(S_{i} \geq S_{j}\right), \quad i=1,2, \ldots, n .
$$

Then, the weight vector is obtained:

$$
W^{\prime}=\left(d^{\prime}\left(A_{1}\right), d^{\prime}\left(A_{2}\right), \ldots, d^{\prime}\left(A_{n}\right)\right)^{T} .
$$

Finally, the normalized weight vector is obtained.

2.3. Application of the Belief Structure for the Fire Risk Calculation. After identifying fire risk factors and establishing the hierarchical structure of the index system, another important task of risk management is to assess the risk, which is an effective way to prevent or reduce the effect of the fire [2]. In this paper, the fire risk of residential buildings is defined as the result of comprehensive measurement associated to the occurrence likelihood and the consequence severity of the fire. The formula is as follows:

$$
P=L \otimes S,
$$

where $P$ is the magnitude of the fire risk presented by various potential fire hazards, $L$ refers to the occurrence likelihood of potential fire hazards or fire risk factors, $S$ implies the consequence severity of potential fire hazards or fire risk factors, and $\otimes$ represents the interconnection relationship between $L$ and $S$.

2.3.1. Fuzzy Linguistic Variables for the Fire Risk. After defining the fire risk, it is necessary to transform the factors into the same form of fuzzy evaluation grade. Due to the uncertainty, analysts tend to use linguistic variable terms rather than precise numerical values to evaluate the fire risk. Therefore, this paper uses a ranking form of fuzzy linguistic variables to represent the fire risk profile of each factor.

A belief degree is generally used to describe the level of expectations for trust events, and it must be less than or equal to 1 to express the degree of which answer is considered true. Individual differences of belief degree depend on assessor's expertise and the knowledge to understand the assessment system. A belief structure can solve the problems of fuzziness, uncertainty, and imprecision in human decision-making. Therefore, this paper presents a model that combines fuzzy linguistic variables and a belief degree to construct a belief structure with the same set of assessment grades [26]. These sets' form of each factor could be expressed as follows:

$$
\begin{aligned}
R_{L} & =\left[R_{L 1}, R_{L 2}, R_{L 3}, R_{L 4}, R_{L 5}\right]=\{\text { highly unlikely, unlikely slight, likely, reasonably likely, highly likely }, \\
R_{S} & =\left[R_{S 1}, R_{S 2}, R_{S 3}, R_{S 4}, R_{S 5}\right]=\{\text { negligible, slight, moderate, serious, catastrophic }\}, \\
R & =\left[R_{1}, R_{2}, R_{3}, R_{4}, R_{5}\right]=\{\text { very low, low, medium, high, very high }\} .
\end{aligned}
$$


TABLE 1: Relative importance described by the triangular fuzzy numbers.

\begin{tabular}{|c|c|c|}
\hline $\begin{array}{l}\text { Relative importance in } \\
\text { qualitative description }\end{array}$ & Description & $\begin{array}{c}\text { Triangular fuzzy } \\
\text { number }\end{array}$ \\
\hline Equally important & Both indexes contribute equally to the target fire risk & $(1,1,2)$ \\
\hline $\begin{array}{l}\text { Between equally and slightly } \\
\text { important }\end{array}$ & Between the front and the back & $(1,2,3)$ \\
\hline Slightly important & $\begin{array}{l}\text { Based on the objective judgment and expert experience, it is considered that one } \\
\text { index contributes slightly more to the target fire risk than another }\end{array}$ & $(2,3,4)$ \\
\hline $\begin{array}{l}\text { Between slightly and strongly } \\
\text { important. }\end{array}$ & Between the front and the back & $(3,4,5)$ \\
\hline Strongly important & $\begin{array}{l}\text { Based on the objective judgment and expert experience, it is considered that the } \\
\text { contribution of one index to the target fire risk is better than another }\end{array}$ & $(4,5,6)$ \\
\hline $\begin{array}{l}\text { Between strongly and very } \\
\text { strongly important }\end{array}$ & Between the front and the back & $(5,6,7)$ \\
\hline Very strongly important & The index's contribution to the target fire risk is significantly better than another & $(6,7,8)$ \\
\hline $\begin{array}{l}\text { Between very strongly and } \\
\text { absolutely important. }\end{array}$ & Between the front and the back & $(7,8,9)$ \\
\hline Absolutely important & $\begin{array}{c}\text { There is evidence that one index is definitely better than another for the target fire } \\
\text { risk }\end{array}$ & $(8,9,9)$ \\
\hline
\end{tabular}

Among them, $R_{L}, R_{S}$, and $R$ represent the evaluation grade variables of the occurrence likelihood of fire, consequence severity of fire, and fire risk, respectively.

2.3.2. Fire Risk Level Based on a Belief Structure. Because of the complexity and uncertainty of the system, the type of membership function is not the dominant factor in the risk assessment analysis of the system [27]. Therefore, as listed in Table 2 and Figure 2, this paper applies the triangular membership function which is the most commonly used one to describe the subjective linguistic variables [15] and adopts the five-phase method, adjusted and modified from Ngai and Wat [28] to represent the occurrence likelihood of fire $(L)$ and the consequence severity of building fire $(S)$, respectively. Suppose that the occurrence likelihood of building fire $(L)$ and the consequence severity of building fire $(S)$ for each factor are independent of each other; they are denoted by triangular fuzzy numbers $\mathrm{FTN}_{L}=\left(a_{L}, b_{L}, c_{L}\right)$ and $\mathrm{FTN}_{S}=\left(b_{S}, b_{S}, c_{S}\right)$. Then, the desired fire risk of each factor can be expressed as

$$
\mathrm{FTN}_{L S}=\mathrm{FTN}_{L} \otimes \mathrm{FTN}_{S}=\left(a_{L} \otimes a_{S}, b_{L} \otimes b_{S}, c_{L} \otimes c_{S}\right) .
$$

Fuzzy risk $P$ with a belief structure can be obtained through the following steps:

(1) According to formula (8), calculate $\mathrm{FTN}_{L S}$ of each factor

(2) Map the calculated $\mathrm{FTN}_{L S}$ to the $\mathrm{FTN}_{P}$ membership curve, and obtain the intersection points of each fuzzy language level variable (note: if there is more than one intersection point on a certain fuzzy language level variable, take the intersection point with the largest longitudinal coordinate value), as shown in Figures 3 and 4

(3) Obtain a set of intersection values $\left(\beta_{P}\right)$, which denote five nonstandardized linguistic variable levels of risk $P$ in the form of fuzzy sets

(4) Normalize $\beta_{P}$, and obtain the basic belief degree $\beta$ of each factor related to its fire risk
As listed in Table 2, if a single factor judged by experts' knowledge and experience takes a fire risk value of that the occurrence likelihood of building fire corresponds to $(0.5,0.75,1)$, the consequence severity of building fire corresponds to $(0.25,0.50,0.75)$. The corresponding value of FTN $_{L S}$ will be $(0.125,0.375,0.75)$. Then, map $\mathrm{FTN}_{L S}$ to $\mathrm{FTN}_{P}$ to get the set of intersection values $\left(\beta_{P}\right)$, shown in Figure 4 . Finally, the basic belief degree $\beta$ is obtained after the normalization of $\beta_{P}$, which denotes that five nonstandardized linguistic variables of very low, low, general, high, and very high correspond to $0.25,0.75,0.8,0.4$, and 0 , respectively.

It is noteworthy that the triangular fuzzy numbers for the occurrence likelihood $(L)$ and the consequence severity $(S)$ of building fire judged by experts cannot be used directly as input data for the synthesis of fire risk results by the evidential reasoning algorithm. They need to convert to five standardized linguistic variable terms before synthesizing the fire risk of each factor [29].

2.4. Synthesizing Assessment Result Using the Evidence Reasoning Algorithm. The theory of evidential reasoning was first proposed by Dempsterin 1967 [30]. Then, in 1976, Shafer further expanded and improved Dempster's work to form a complete and systematic theory [31]. Subsequently, in commemoration of Dempster and Shafer's contribution to the theory of evidence reasoning, the theory was often called Dempster-Shafer theory or D-S theory for abbreviation. D-S theory can be used to deal with uncertain, imprecise, and or inaccurate information. It was originally used as an approximate reasoning tool for information synthesis in expert systems [32]. Later, it was applied to the decision-making judgment of uncertain problems [33]. Due to the uncertainty of the changing system environment and qualitative descriptive information and to consider the influence of the weight in the synthesis of evidence, evidence reasoning algorithm (ER algorithm) was proposed [34].

After knowing the basic belief degree $\beta$ and the weight $\omega$ of each factor, suppose $m_{n, i}$ is a basic probability mass, 
TABLE 2: Linguistic variables described by the triangular membership number.

\begin{tabular}{lcr}
\hline Likelihood of building fire $(L)$ & Severity of building fire $(S)$ & Triangular fuzzy number \\
\hline Highly unlikely (HU) & Negligible (NE) & $(0.00,0.00,0.25)$ \\
Unlikely slight (US) & Slight (SL) & $(0.00,0.25,0.50)$ \\
Likely (LI) & Moderate (MO) & $(0.25,0.50,0.75)$ \\
Reasonably likely (RL) & Serious (SE) & $(0.50,0.75,1.00)$ \\
Highly likely (HL) & Catastrophic (CA) & $(0.75,1.00,1.00)$ \\
\hline
\end{tabular}

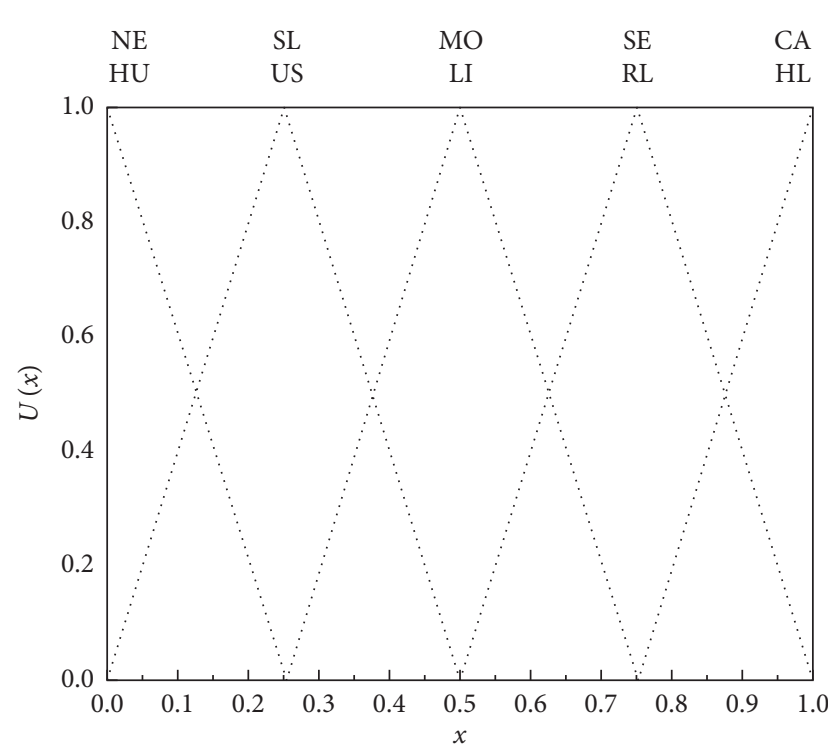

Figure 3: Triangular fuzzy membership function.

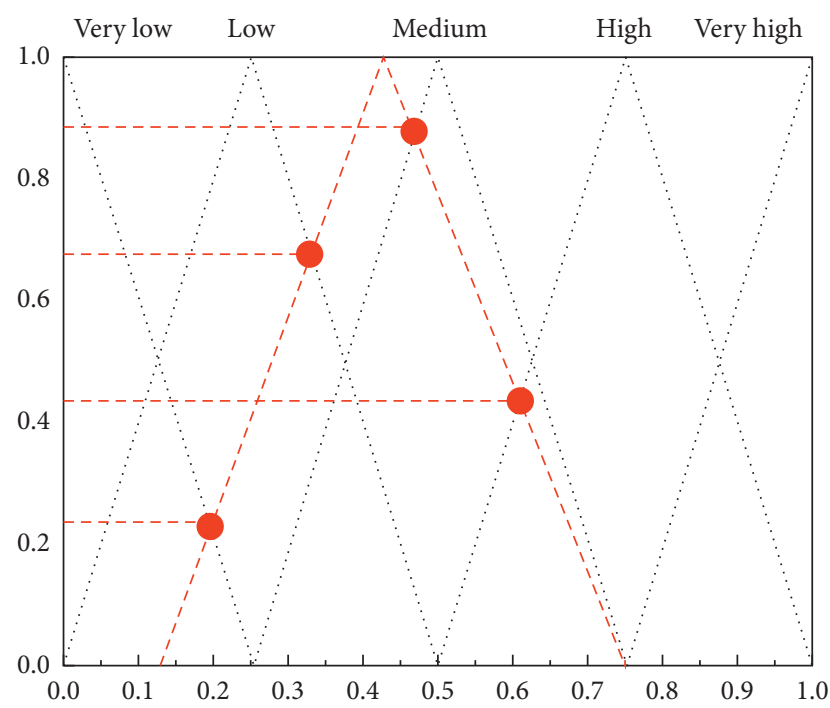

Figure 4: An example of mapping $\mathbf{F T N}_{\mathrm{LS}}$ to $\mathbf{F T N}_{\mathbf{P}}$.

denoting the degree to which the $i$-th basic factor $\mathrm{e}_{i}$ supports the general factor $y$ to be evaluated as the $n$-th grade:

$$
m_{n, i}=\omega_{i} \beta_{n, i}, \quad n=1, \ldots, N .
$$

The unassigned probability mass $m_{H, i}$ is composed of two parts, which represent the unassigned mass function $\bar{m}_{H, i}$ due to the weight and the unassigned mass function $\widetilde{m}_{H, i}$ due to the lack of information and incompleteness:

$$
\begin{aligned}
& m_{H, i}=1-\sum_{n=1}^{N} m_{n, i}=1-\omega_{i} \sum_{n=1}^{N} \beta_{n, i} \\
& m_{H, i}=\bar{m}_{H, i}+\widetilde{m}_{H, i}, \\
& \bar{m}_{H, i}=1-\omega_{i}, \\
& \widetilde{m}_{H, i}=\omega_{i}\left(1-\sum_{n=1}^{N} \beta_{n, i}\right) .
\end{aligned}
$$

Suppose $m_{n, I(i+1)}$ represent the combined masses of $i$ basic factors synthesized on the $n$-th evaluation grade. Suppose $m_{H, I(i+1)}$ represent the unassigned probability mass to the first $i$ basic factors. The formula is as follows:

$$
\begin{aligned}
&\left\{H_{n}\right\}: m_{n, I(i+1)}= K_{I(i+1)}\left[m_{n, I(i)} m_{n, i+1}+m_{H, I(i)} m_{n, i+1}\right. \\
&\left.+m_{n, I(i)} m_{H, i+1}\right], \\
&\{H\}: \bar{m}_{H, I(i+1)}= K_{I(i+1)}\left[\bar{m}_{H, I(i)}+\bar{m}_{H, i+1}\right], \\
&\{H\}: \widetilde{m}_{H, I(i+1)}= K_{I(i+1)}\left[\tilde{m}_{H, I(i)} \tilde{m}_{H, i+1}+\bar{m}_{H, I(i)} \tilde{m}_{H, i+1}\right. \\
&\left.+\tilde{m}_{H, I(i)} \bar{m}_{H, i+1}\right], \\
& K_{I(i+1)}=\left[\begin{array}{c}
N \\
1-\sum_{t=1}^{N} \sum_{j=1}^{N} m_{t, I(i)} m_{j, i+1}
\end{array}\right]^{-1}, i=1, \ldots, L-1,
\end{aligned}
$$

where $K_{I(i+1)}$ represents the normalizing factor, which reflects the degree of conflict between the indicators (evidence). Suppose that there is a total of $L$ basic factors for evaluation objectives; then, $m_{n, I(L)}, \bar{m}_{H, I(L)}$, and $\tilde{m}_{H, I(L)}$ are obtained by iteration calculation. After that, the combined belief degree can be obtained by the following normalization process:

$$
\begin{aligned}
& \left\{H_{n}\right\}: \beta_{n}=\frac{m_{n, I(i)}}{1-\bar{m}_{H, I(L)}}, \\
& \{H\}: \beta_{H}=\frac{\widetilde{m}_{H, I(L)}}{1-\bar{m}_{H, I(L)}},
\end{aligned}
$$

where $\beta_{H}$ represents the unassigned belief degree to the general factor $y$ after aggregation. $\beta_{n}$ and $\beta_{H}$ represent the comprehensive belief degree to the evaluation object. 
2.5. Obtaining a Clear Result Using the Expected Utility Method. In fact, the belief degree vector obtained in the former evaluation is the trust distribution of risk under the identification framework, and the result cannot be shown clearly. For example, the identification framework of a building fire risk (i.e., assessment set) is recorded as "very low," "low," "general," "high," and "very high." Suppose that the combined degree of the belief vector is $(0,0.45,0.5,0.05,0)$, calculated by the above formula, which means that the construction risk level corresponds to a "low" level of $45 \%$, a "general" level of 50\%, and a "high" level of 5\%. However, this information cannot clearly indicate the magnitude of the fire risk. Therefore, the concept of utility value is introduced in [35] as follows:

$$
u(y)=\sum_{n=1}^{N} \beta_{n} u\left(H_{n}\right)
$$

where $u\left(H_{n}\right)$ represents the utility of the evaluation grade $H_{n}$. In order to further clarify the level of the fire risk corresponding to the utility value, it is necessary to classify the grade of the fire risk. This paper presents the classification as shown in Table 3.

Quantitative evaluation results (utility values) can be obtained by processing the above methods. However, if the basic attribute (factor) information is incomplete or the expert's information about the factor is uncertain, the result obtained by the ER algorithm is also uncertain. [34, 36-38] refer to the concept of utility interval and conquer this problem through minimum utility $u_{\min }(y)$, maximum utility $u_{\max }(y)$, and average utility $u_{\text {avg }}(y)$ :

$$
\begin{aligned}
& u_{\text {min }}(y)=\left(\beta_{1}+\beta_{H}\right) u\left(H_{1}\right)+\sum_{n=2}^{N} \beta_{n} u\left(H_{n}\right), \\
& u_{\max }(y)=\sum_{n=1}^{N-1} \beta_{n} u\left(H_{n}\right)+\left(\beta_{N}+\beta_{H}\right) u\left(H_{N}\right), \\
& u_{\mathrm{avg}}(y)=\frac{u_{\max }(y)+u_{\min }(y)}{2} .
\end{aligned}
$$

2.6. Verification of the Model Using Sensitivity Analysis. Due to the influence of external factors, input values obtained from different experts or the same experts in different periods are different. Consequently, the uncertainty is inherent in fire risk assessment. In this paper, a sensitivity analysis method is introduced for studying and predicting the disturbance degree of the model output value (risk magnitude) caused by the change of the input value of each index. Sensitivity analysis is a systematic analysis method, which identifies weak points or areas in the system with the insight of managers in quantitative evaluation and continuously improves the design of the system and improves the stability of the system [39].

If the validated model is reliable and its reasoning process is logically feasible, then the sensitivity analysis of the model at least satisfies the following three theorems:
(1) A slight increase/decrease in the degrees of belief at any linguistic variables of the lowest-level factors will result in increase/decrease in the fire risk level of the output of the model

(2) If the belief degree at the lowest preference linguistic variable of the lowest-level factors increases by $p$ and $q$ (meanwhile, the belief degree at the highest preference linguistic variable decreases by $p$ and $q$ $(1>q>p))$ and the utility values of the model output are $u_{p}$ and $u_{q}$, then $u_{p}$ should be greater than $u_{p}$

(3) In the lowest-level factors, the total influence of $x$ factors on the output of the model is always greater than that of $x-y(y \in x)$ factor sets

\section{Case Study}

Three residential buildings marked from BUILDING-1 to BUILDING-3 were selected as a case study to illustrate the proposed fire risk model. This paper takes BUILDING-1, for example, to describe the calculation process of the model step by step. Based on the hierarchical structure of the fire risk model in Figure 2 and the available information in [40], the fire risk of BUILDING-1can be assessed through the following steps.

3.1. Develop a Generic Fire Risk Model for BUILDING-1. At this phase, the identified fire risk factors and a generic fire risk model are presented in Figure 1. The index system of fire risk assessment mainly consists of three levels, including the total target risk, the first-level factor set, and the second-level factor set. According to Wang et al. [41], fuzzy linguistic terms for risk expression are used for effective information processing in the range of 4 to 7 . Therefore, this study uses five linguistic terms to denote the assessment of fire risk based on the viewpoint of experts in the field.

3.2. Determine the Weights of Each Factor. Given the hierarchical structure of fire risk in Figure 2, the weight calculations for fire risk factors are conducted. The weight calculations of factors U1, U2, U3, U4, and U5 are taken as an example. Firstly, the judgment matrix is constructed through the pairwise comparison of these five factors by experts (according to Table 1) and presented in Table 4. Then, according to equations (3) and (4), the value of synthetic extent $S_{i}$ and the possibility degree $d^{\prime}\left(A_{i}\right)$ of each factor are obtained, respectively. Finally, the normalized weight vector for five factors is obtained. Using a similar way, the weights of all factors can be calculated and listed in Table 5.

3.3. Application of the Belief Structure for Fire Risk in BUILDING-1. According to the actual situation of BUILDING-1 fire safety, the occurrence likelihood of fire $(L)$ and the consequence severity of fire $(S)$ for each bottom index should be scored, and the scoring standards are mainly based on the code for fire-protection design of buildings (GB50016-2014) [42], code for fire prevention in design of 
TABLE 3: Classification of the building fire risk level.

\begin{tabular}{lcc}
\hline Fire risk level & Risk interval & Risk description and measures \\
\hline Very low & $(0.00,0.06]$ & Risks are negligible. \\
Low & $(0.06,0.25]$ & Risks are acceptable, but if cost-effectiveness is reasonable, measures can be taken to reduce risks. \\
Moderate & $(0.25,0.44]$ & Risks are tolerable and, if feasible, measures must be taken to reduce them. \\
High & $(0.44,0.72]$ & Measures must be taken to reduce risks. \\
Very high & $(0.72,1.00]$ & Risk is unacceptable. Measures must be taken to reduce the risk and control it effectively. \\
\hline
\end{tabular}

Table 4: Triangular fuzzy judgment matrix of indexes U1-U5.

\begin{tabular}{|c|c|c|c|c|c|}
\hline$R$ & U1 & U2 & U3 & U4 & U5 \\
\hline Expert 1 & $(1,1,2)$ & $(2,3,4)$ & $(2,3,4)$ & $(2,3,4)$ & $(1,2,3)$ \\
\hline Expert 2 & $(1,1,2)$ & $(2,3,4)$ & $(1,2,3)$ & $(1,2,3)$ & $(3,4,5)$ \\
\hline Expert 3 & $(1,1,2)$ & $(3,4,5)$ & $(2,3,4)$ & $(2,3,4)$ & $(1,2,3)$ \\
\hline Expert 4 & $(1,1,2)$ & $(2,3,4)$ & $(2,3,4)$ & $(1,2,3)$ & $(1,2,3)$ \\
\hline Expert 5 & $(1,1,2)$ & $(2,3,4)$ & $(2,3,4)$ & $(2,3,4)$ & $(3,4,5)$ \\
\hline Expert 6 & $(1,1,2)$ & $(3,4,5)$ & $(1,2,3)$ & $(2,3,4)$ & $(1,2,3)$ \\
\hline $\mathrm{U} 1$ & $(1,1,2)$ & $(2.33,3.33,4.33)$ & $(1.67,2.67,3.67)$ & $(1.67,2.67,3.67)$ & $(1.67,2.67,3.67)$ \\
\hline Expert 1 & $(0.25,0.33,0.5)$ & $(1,1,2)$ & $(0.33,0.5,1)$ & $(1,1,2)$ & $(1,1,2)$ \\
\hline Expert 2 & $(0.25,0.33,0.5)$ & $(1,1,2)$ & $(0.25,0.33,0.5)$ & $(1,1,2)$ & $(1,2,3)$ \\
\hline Expert 3 & $(0.2,0.25,0.33)$ & $(1,1,2)$ & $(0.5,1,1)$ & $(1,1,2)$ & $(0.5,1,1)$ \\
\hline Expert 4 & $(0.25,0.33,0.5)$ & $(1,1,2)$ & $(0.33,0.5,1)$ & $(1,1,2)$ & $(0.5,1,1)$ \\
\hline Expert 5 & $(0.25,0.33,0.5)$ & $(1,1,2)$ & $(0.25,0.33,0.5)$ & $(1,1,2)$ & $(1,2,3)$ \\
\hline Expert 6 & $(0.2,0.25,0.33)$ & $(1,1,2)$ & $(0.5,1,1)$ & $(1,1,2)$ & $(1,1,2)$ \\
\hline $\mathrm{U} 2$ & $(0.23,0.31,0.44)$ & $(1,1,2)$ & $(0.36,0.61,0.83)$ & $(1,1,2)$ & $(0.83,1.33,2)$ \\
\hline Expert 1 & $(0.25,0.33,0.5)$ & $(1,2,3)$ & $(1,1,2)$ & $(1,1,2)$ & $(1,2,3)$ \\
\hline Expert 2 & $(0.33,0.5,1)$ & $(2,3,4)$ & $(1,1,2)$ & $(1,2,3)$ & $(1,2,3)$ \\
\hline Expert 3 & $(0.25,0.33,0.5)$ & $(1,1,2)$ & $(1,1,2)$ & $(1,2,3)$ & $(1,1,2)$ \\
\hline Expert 4 & $(0.25,0.33,0.5)$ & $(1,2,3)$ & $(1,1,2)$ & $(1,1,2)$ & $(1,1,2)$ \\
\hline Expert 5 & $(0.25,0.33,0.5)$ & $(2,3,4)$ & $(1,1,2)$ & $(1,2,3)$ & $(1,2,3)$ \\
\hline Expert 6 & $(0.33,0.5,1)$ & $(1,1,2)$ & $(1,1,2)$ & $(1,2,3)$ & $(1,2,3)$ \\
\hline $\mathrm{U} 3$ & $(0.28,0.39,0.67)$ & $(1.33,2,3)$ & $(1,1,2)$ & $(1,1.67,2.67)$ & $(1,1.67,2.67)$ \\
\hline Expert 1 & $(0.33,0.5,1)$ & $(0.5,1,1)$ & $(0.5,1,1)$ & $(1,1,2)$ & $(1,1,2)$ \\
\hline Expert 2 & $(0.25,0.33,0.5)$ & $(0.5,1,1)$ & $(0.5,1,1)$ & $(1,1,2)$ & $(1,1,2)$ \\
\hline Expert 3 & $(0.33,0.5,1)$ & $(0.5,1,1)$ & $(0.33,0.5,1)$ & $(1,1,2)$ & $(0.5,1,1)$ \\
\hline Expert 4 & $(0.25,0.33,0.5)$ & $(0.5,1,1)$ & $(0.5,1,1)$ & $(1,1,2)$ & $(0.5,1,1)$ \\
\hline Expert 5 & $(0.33,0.5,1)$ & $(0.5,1,1)$ & $(0.5,1,1)$ & $(1,1,2)$ & $(1,1,2)$ \\
\hline Expert 6 & $(0.33,0.5,1)$ & $(0.5,1,1)$ & $(0.33,0.5,1)$ & $(1,1,2)$ & $(1,1,2)$ \\
\hline $\mathrm{U} 4$ & $(0.28,0.39,0.67)$ & $(0.5,1,1)$ & $(0.33,0.5,1)$ & $(1,1,2)$ & $(0.83,1,1.67)$ \\
\hline Expert 1 & $(0.33,0.5,1)$ & $(0.5,1,1)$ & $(0.33,0.5,1)$ & $(0.5,1,1)$ & $(1,1,2)$ \\
\hline Expert 2 & $(0.2,0.25,0.33)$ & $(0.33,0.5,1)$ & $(0.33,0.5,1)$ & $(0.5,1,1)$ & $(1,1,2)$ \\
\hline Expert 3 & $(0.33,0.5,1)$ & $(1,1,2)$ & $(0.5,1,1)$ & $(1,1,2)$ & $(1,1,2)$ \\
\hline Expert 4 & $(0.33,0.5,1)$ & $(1,1,2)$ & $(0.5,1,1)$ & $(1,1,2)$ & $(1,1,2)$ \\
\hline Expert 5 & $(0.2,0.25,0.33)$ & $(0.33,0.5,1)$ & $(0.33,0.5,1)$ & $(0.5,1,1)$ & $(1,1,2)$ \\
\hline Expert 6 & $(0.33,0.5,1)$ & $(0.5,1,1)$ & $(0.33,0.5,1)$ & $(0.5,1,1)$ & $(1,1,2)$ \\
\hline U5 & $(0.29,0.42,0.78)$ & $(0.61,0.83,1.33)$ & $(0.39,0.67,1)$ & $(0.67,1,1.33)$ & $(1,1,2)$ \\
\hline
\end{tabular}

interior decoration of buildings (GB 50222-2017) [43], guidance on building fire risk assessment for property insurance, and CIB W14 Workshop Report [44]. For example, the detailed scoring rules of index U15 (building service life) and index U4 (property fire management) are shown in Table 6. According to these rules, it is easy to obtain the value of $\mathrm{FTN}_{L}$ and $\mathrm{FTN}_{s}$ of each bottom index. Accordingly, by utilising equation (8), the fire risk of each bottom index is presented in Table 7 in the form of $\mathrm{FTN}_{L S}$. Then, $\mathrm{FTN}_{L S}$ is mapped to $\mathrm{FTN}_{P}$ for obtaining the intersection point. Finally, the basic belief degree $\beta$ is obtained after the normalization of $\beta_{\mathbf{P}}$, and the results are shown in Table 8 .
3.4. Synthesizing Assessment Result Using the Evidence Reasoning Algorithm. On the premise that the weight of each index was obtained, the aggregation calculations for U11, U12, U13, U14, U15, and U16 were implemented according to the D-S operator (equations (9)-(20)); then, the aggregation result of disaster-causing factor $\mathrm{U} 1$ is obtained. Similarly, the aggregation results of passive measures $\mathrm{U} 2$, active measures $\mathrm{U} 3$, property fire management $\mathrm{U} 4$, the rescue capability of fire brigade U5 and the objective fire risk $R$ can also be obtained, and the results of the first-level index are presented in Table 9 . 
TABLE 5: Weights of fire risk factors.

\begin{tabular}{lcc}
\hline Fire risk factors & Abbreviation & Weights \\
\hline Disaster-causing factors & $\mathrm{U} 1$ & 0.364 \\
Passive measures & $\mathrm{U} 2$ & 0.149 \\
Active measures & $\mathrm{U} 3$ & 0.244 \\
Property fire management & $\mathrm{U} 4$ & 0.122 \\
The rescue capability of fire brigade & $\mathrm{U} 11$ \\
Electrical equipment & $\mathrm{U} 12$ \\
Occupant density & $\mathrm{U} 13$ \\
Gas use mode & $\mathrm{U} 14$ \\
Interior decoration & $\mathrm{U} 15$ \\
Building service life & $\mathrm{U} 16$ \\
Ambient & $\mathrm{U} 21$ \\
Fire resistance rating & $\mathrm{U} 22$ \\
Fire compartment & $\mathrm{U} 23$ \\
Safe evacuation & $\mathrm{U} 24$ \\
Fire separation distance & $\mathrm{U} 31$ \\
Indoor hydrant water supply system & $\mathrm{U} 32$ \\
Portable fire-extinguisher apparatus & $\mathrm{U} 33$ \\
Safety monitoring system & $\mathrm{U} 51$ \\
Fire lane & $\mathrm{U} 52$ \\
Fighting capability of fire brigade & $\mathrm{U} 53$ \\
Water supply system of outdoor fire hydrant & 0.276 \\
\hline
\end{tabular}

TABle 6: Detailed scoring rules of U15 and U4.

\begin{tabular}{|c|c|c|c|c|}
\hline Indexes & Detailed scoring rules & Score $(L)$ & Score $(S)$ & Remarks \\
\hline $\begin{array}{l}\text { U15-building } \\
\text { service life }\end{array}$ & $\begin{array}{l}\text { (1) } 0<\text { service life }<n / 5 \\
\text { (2) } n / 5<\text { service life } \leq 2 n / 5 \\
\text { (3) } 2 n / 5<\text { service life } \leq 3 n / 5 \\
\text { (4) } 3 n / 5<\text { service life } \leq 4 n / 5 \\
\text { (5) Service life }<4 n / 5\end{array}$ & $\begin{array}{l}(0.00,0.00,0.25) \\
(0.00,0.25,0.50) \\
(0.25,0.50,0.75) \\
(0.50,0.75,1.00) \\
(0.75,1.00,1.00)\end{array}$ & $\begin{array}{l}(0.00,0.00,0.25) \\
(0.00,0.25,0.50) \\
(0.25,0.50,0.75) \\
(0.50,0.75,1.00) \\
(0.75,1.00,1.00)\end{array}$ & $n$ is the design life \\
\hline
\end{tabular}

Including four aspects:

(1) There are full-time fire safety management personnel with prejob training

U4-property fire management
(1) Four aspects are perfect

(2) Any aspects are not perfect

(3) All four aspects are not perfect
$(0.25,0.50,0.75) \quad(0.25,0.50,0.75)$ $(0.25,0.50,0.75)(0.25,0.50,0.75)$ established, and the responsibility is clear

$(0.50,0.75,1.00)(0.50,0.75,1.00) \quad$ (3) The hidden danger is checked and recorded every day

(4) Regular inspection of fire facilities and timely maintenance

TABLe 7: The fire risk of each factor.

\begin{tabular}{lccc}
\hline Fire risk factors & FTN $_{L}$ & FTN $_{S}$ & \multicolumn{1}{c}{ FTN $_{L S}$} \\
\hline U11 & $(0,0,0.25)$ & $(0,0.25,0.5)$ & $(0,0,0.13)$ \\
U12 & $(0.25,0.5,0.75)$ & $(0.25,0.5,0.75)$ & $(0.06,0.25,0.56)$ \\
U13 & $(0,0.25 .0 .5)$ & $(0.25,0.5,0.75)$ & $(0,0.06,0.25)$ \\
U14 & $(0.5,0.75,1)$ & $(0.5,0.75,1)$ & $(0.25,0.56,1)$ \\
U15 & $(0.25,0.5,0.75)$ & $(0.25,0.5,0.75)$ & $(0.06,0.25,0.56)$ \\
U16 & $(0,0,0.25)$ & $(0,0,0.25)$ & $(0,0,0.06)$ \\
U21 & $(0.25,0.5,0.75)$ & $(0.25,0.5,0.75)$ & $(0,0.13,0.38)$ \\
U22 & $(0.25,0.5,0.75)$ & $(0,0.25 .0 .5)$ & $(0.06,0.25,0.56)$ \\
U23 & $(0.25,0.5,0.75)$ & $(0.25,0.5,0.75)$ & $(0,0,0.06)$ \\
U24 & $(0,0,0.25)$ & $(0,0,0.25)$ & $(0.06,0.25,0.56)$ \\
U31 & $(0.25,0.5,0.75)$ & $(0.25,0.5,0.75)$ & $(0,0.13,0.38)$ \\
U32 & $(0.25,0.5,0.75)$ & $(0,0.25 .0 .5)$ & $(0,0.06,0.25)$ \\
U33 & $(0,0.25 .0 .5)$ & $(0,0.25 .0 .5)$ & $(0.06,0.25,0.56)$ \\
U4 & $(0.25,0.5,0.75)$ & $(0.25,0.5,0.75)$ & $(0,0,0.19)$ \\
U51 & $(0.25,0.5,0.75)$ & $(0,0,0.25)$ & $(0,0.13,0.38)$ \\
U52 & $(0.25,0.5,0.75)$ & $(0,0.25 .0 .5)$ & $(0,0.13,0.38)$ \\
U53 & $(0.25,0.5,0.75)$ & $(0,0.25 .0 .5)$ & \\
\hline
\end{tabular}


TABLE 8: Intersection results of fire risk factors.

\begin{tabular}{|c|c|c|c|c|c|c|c|c|c|c|}
\hline \multirow{2}{*}{ Fire risk factors } & \multicolumn{5}{|c|}{$\beta_{\mathbf{P}}$} & \multicolumn{5}{|c|}{$\beta$} \\
\hline & VL & $\mathbf{L}$ & $\mathbf{M}$ & $\mathbf{H}$ & VH & VL & $\mathbf{L}$ & $\mathbf{M}$ & $\mathbf{H}$ & VH \\
\hline U11 & 1 & 0.33 & 0 & 0 & 0 & 0.75 & 0.25 & 0 & 0 & 0 \\
\hline U12 & 0.25 & 0.75 & 0.8 & 0.4 & 0 & 0.11 & 0.34 & 0.36 & 0.18 & 0 \\
\hline U13 & 0.67 & 0.75 & 0.25 & 0 & 0 & 0.4 & 0.45 & 0.15 & 0 & 0 \\
\hline U14 & 0 & 0.44 & 0.89 & 0.73 & 0.36 & 0 & 0.18 & 0.37 & 0.3 & 0.15 \\
\hline U15 & 0.43 & 1 & 0.56 & 0.11 & 0 & 0.2 & 0.48 & 0.27 & 0.05 & 0 \\
\hline U16 & 0.8 & 0.57 & 0 & 0 & 0 & 0.58 & 0.42 & 0 & 0 & 0 \\
\hline U21 & 0.43 & 1 & 0.56 & 0.11 & 0 & 0.2 & 0.48 & 0.27 & 0.05 & 0 \\
\hline U22 & 0.67 & 0.75 & 0.25 & 0 & 0 & 0.4 & 0.45 & 0.15 & 0 & 0 \\
\hline $\mathrm{U} 23$ & 0.43 & 1 & 0.56 & 0.11 & 0 & 0.2 & 0.48 & 0.27 & 0.05 & 0 \\
\hline $\mathrm{U} 24$ & 1 & 0.2 & 0 & 0 & 0 & 0.83 & 0.17 & 0 & 0 & 0 \\
\hline U31 & 0.43 & 1 & 0.56 & 0.11 & 0 & 0.2 & 0.48 & 0.27 & 0.05 & 0 \\
\hline U32 & 0.67 & 0.75 & 0.25 & 0 & 0 & 0.4 & 0.45 & 0.15 & 0 & 0 \\
\hline U33 & 0.8 & 0.57 & 0 & 0 & 0 & 0.58 & 0.42 & 0 & 0 & 0 \\
\hline U4 & 0.43 & 1 & 0.56 & 0.11 & 0 & 0.2 & 0.48 & 0.27 & 0.05 & 0 \\
\hline U51 & 1 & 0.43 & 0 & 0 & 0 & 0.7 & 0.3 & 0 & 0 & 0 \\
\hline U52 & 0.67 & 0.75 & 0.25 & 0 & 0 & 0.4 & 0.45 & 0.15 & 0 & 0 \\
\hline U53 & 0.67 & 0.75 & 0.25 & 0 & 0 & 0.4 & 0.45 & 0.15 & 0 & 0 \\
\hline
\end{tabular}

Table 9: Aggregation of fire risk factors.

\begin{tabular}{|c|c|c|c|c|c|}
\hline Fire risk factors & Very low & Low & Moderate & High & Very high \\
\hline Disaster-causing factors U1 & 0.3875 & 0.3515 & 0.1753 & 0.0721 & 0.0136 \\
\hline Passive measures U2 & 0.2555 & 0.4841 & 0.2234 & 0.0370 & 0 \\
\hline Active measures U3 & 0.3898 & 0.4679 & 0.1277 & 0.0146 & 0 \\
\hline Property fire management U4 & 0.2045 & 0.4773 & 0.2652 & 0.0530 & 0 \\
\hline The rescue capability of fire brigade U5 & 0.5099 & 0.4015 & 0.0886 & 0 & 0 \\
\hline Objective fire risk $R$ & 0.3644 & 0.4332 & 0.1572 & 0.0383 & 0.0049 \\
\hline
\end{tabular}

3.5. The Target Fire Risk Assessment Using the Expected Utility Method. From Table 9, the objective fire risk $R$ corresponding to five-level linguistic terms can be expressed as $R=\{\mathrm{VL}(0.36), \mathrm{L}(0.43), \mathrm{M}(0.16) \mathrm{H}(0.04)$, VH (0.005) , which cannot reveal the magnitude of the target fire risk in a clear way. Thus, the final fire risk (FR) is evaluated using equation (21), and the result is 0.2205, shown in Table 10. According to Table 3, it could be observed that the objective fire risk $R$ is acceptable, but if cost-effectiveness is reasonable, measures can be taken in this building to reduce its fire risks.

3.6. Sensitivity Analysis. In order to verify the model, the degrees of belief at the lowest preference linguistic variable of the lowest-level factors should increase by $10 \%, 20 \%$, and $30 \%$ (meanwhile, the degrees of belief at the highest preference linguistic variable decrease by $10 \%, 20 \%$, and $30 \%$ ). The model output data are tabulated in Table 11, and the graphic display results are listed in Figure 5. It is obvious that all the results are consistent with theorems 1 and 2, respectively. According to theorem 3, if the model is logically reasonable and feasible, the belief degree at the lowest level of the hierarchy structure associated with $x$ factors will always be smaller than the one associated with $x-y(y \in x)$ factors. This can be illustrated by comparing the results of different input data, such as if the belief degree at the lowest preference linguistic variable associated with all the lowestlevel factors increases by $10 \%$ (simultaneously, the one at the highest preference linguistic variable decreases by $10 \%$ ), the output utility value is 0.1717 . However, if the belief degree at the lowest preference linguistic variable associated with U11, U12, U13, U14, U15, U16, U21, U22, U23, U24, U31, U32, and U33 factors increases by $10 \%$ (simultaneously, the one at the highest preference linguistic variable decreases by $10 \%$ ), the output utility value is 0.1826 . Considering that 0.1717 is smaller than 0.1826 , it can be concluded that the verified model satisfies theorem 3 .

\section{Results and Discussion}

Based on the results of the case study in Table 12 and Figure 6, it can be observed that the fire risk level of three buildings corresponds to "moderate" or below. However, it is noteworthy to mention that some aspects should be paid attention to.

In the aspect of disaster-causing factor U1: since the service life of the three residential buildings is less than 10 years and there is no dangerous disaster-causing factor in the internal and external environment of these buildings, the fire risk corresponding to U1 of these buildings is all acceptable.

In the aspect of passive measures U2: U2 of BUILDING2 and BUILDING-3 was higher than that of BUILDING-1. This was mainly due to obstruction of safe evacuation in the 
TABLE 10: Utility value for measuring the building fire risk.

\begin{tabular}{|c|c|c|c|c|c|}
\hline Rating $H_{n}$ & Very low & Low & Moderate & High & Very high \\
\hline$\overline{V_{n}}$ & 1 & 2 & 3 & 4 & 5 \\
\hline$u\left(H_{n}\right)$ & 0 & 0.25 & 0.5 & 0.75 & 1 \\
\hline$\beta_{n}$ & 0.3664 & 0.4332 & 0.1572 & 0.0383 & 0.0049 \\
\hline $\begin{array}{l}\beta_{n} \times u\left(H_{n}\right) \\
\operatorname{FR}=\sum_{n=1}^{N} \beta\end{array}$ & $205^{0}$ & 0.1083 & 0.0786 & 0.0287 & 0.0049 \\
\hline
\end{tabular}

TABLE 11: Increase/decrease model input data.

Increase the input data at the lowest preference linguistic variable; meanwhile, decrease the input data at the highest preference linguistic variable

\begin{tabular}{lccc}
\hline Fire risk factors & $10 \%$ & $20 \%$ & $30 \%$ \\
\hline U12 & 0.2116 & 0.2054 & 0.1997 \\
U11 & 0.2123 & 0.2069 & 0.2026 \\
U4 & 0.2128 & 0.2076 & 0.2041 \\
U32 & 0.2138 & 0.2094 & 0.2050 \\
U31 & 0.2142 & 0.210 & 0.2069 \\
U21 & 0.2146 & 0.2108 & 0.2082 \\
U14 & 0.2155 & 0.2121 & 0.2089 \\
U13 & 0.2163 & 0.2132 & 0.2102 \\
U33 & 0.2168 & 0.2143 & 0.2118 \\
U52 & 0.2170 & 0.2152 & 0.2134 \\
U23 & 0.2172 & 0.2153 & 0.2138 \\
U53 & 0.2174 & 0.2160 & 0.2147 \\
U22 & 0.2179 & 0.2168 & 0.2156 \\
U51 & 0.2180 & 0.2168 & 0.2160 \\
U16 & 0.2181 & 0.2170 & 0.2161 \\
U15 & 0.2182 & 0.2173 & 0.2164 \\
U24 & 0.2191 & 0.2184 & 0.2177 \\
\hline
\end{tabular}

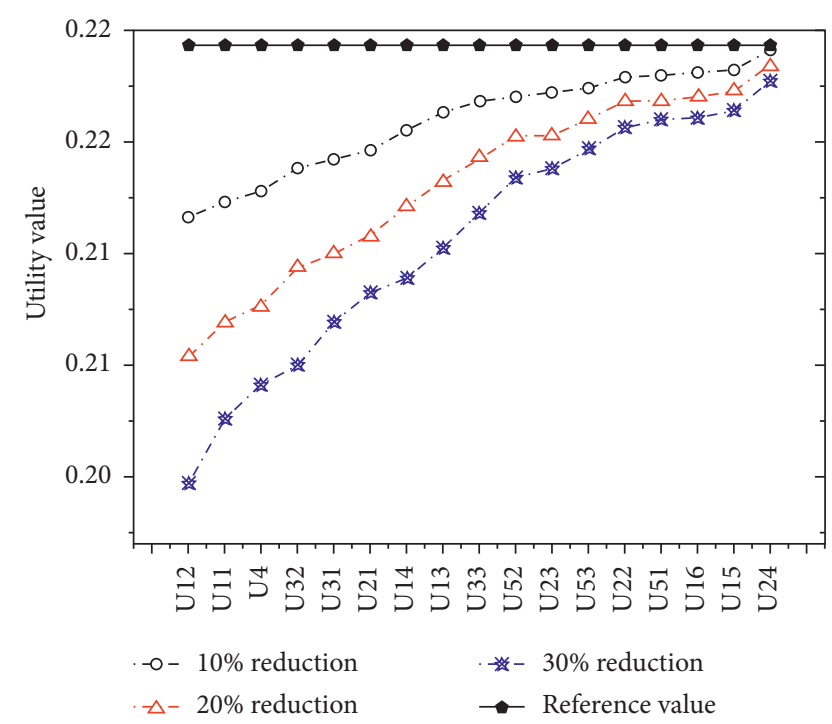

FIgURE 5: Sensitivity analysis of model output data.

stairwell of BUILDING-2 and BUILDING-3, such as some evacuation passageways are littered with debris and some safety evacuation signs are missing, which mean that the residents may fail to evacuate from these buildings in case of a fire.
TABLE 12: Fire risk levels of three buildings.

\begin{tabular}{lcccccc}
\hline Target building & $\mathrm{U} 1$ & $\mathrm{U} 2$ & $\mathrm{U} 3$ & $\mathrm{U} 4$ & $\mathrm{U} 5$ & $\mathrm{U}$ \\
\hline BUILDING-1 & 0.2432 & 0.2604 & 0.1918 & 0.2916 & 0.1447 & 0.2205 \\
BUILDING-2 & 0.2264 & 0.3804 & 0.1921 & 0.4034 & 0.2691 & 0.2511 \\
BUILDING-3 & 0.2398 & 0.3779 & 0.3367 & 0.6042 & 0.2558 & 0.3073 \\
\hline
\end{tabular}

In the aspect of active measures $\mathrm{U} 3$ and property fire management U4: U3 and U4 of BUILDING-3 were higher than those of BUILDING-1 and BUILDING-2. This was mainly due to the lack of regular maintenance of fire-fighting equipment in BUILDING-3. It can be assured that if there is no regular maintenance and inspection, the reliability of firefighting equipment will be reduced. In BUILDING-3, it was found that some fire-fighting equipment were rusty or even abandoned, such as safety monitoring device was out of use, and the fire extinguisher was out of the service date range. In addition, U4 of BUILDING-2 was higher than that of BUILDING-1. This is mainly because that, in BUILDING-2, there is no prejob training of safety management personnel, and daily fire hazard investigation is not carried out.

In the aspect of the rescue capability of fire brigade U5: BUILDING- 2 and BUILDING-3 are all located in CBD of the city. It means that the traffic around the buildings is congested, and the nearby fire brigade may not be able to arrive in time. In particular, BUILDING-2 is further away from the fire brigade than BUILDING-3.

Furthermore, the fire risk of residential buildings is determined by many factors in the complex external environment. It is noteworthy from the analysis that a slight change will lead to the corresponding change in the output value of the model. According to Figure 5, it is obvious that the fire risk model is more sensitive to occupant density U12, electrical equipment U11, property fire management U4, portable fire-extinguisher apparatus U32, and indoor hydrant water supply system U31 than other factors. In other words, the uncertainty of these factors has a relatively large influence on the disturbance of the model system. Therefore, the most effective way to reduce the fire risk of residential buildings is to control these five indicators at first. The analysis results are also consistent with the actual fire prevention measures.

In the previous studies [40,45], grey correlation method and fuzzy clustering method were applied for fire risk assessment in these buildings of China, and the results of these studies are in accordance with the results of our research, which indicated that the presented model is logically feasible and can still maintain its specific function under turbulence or uncertainty conditions. 


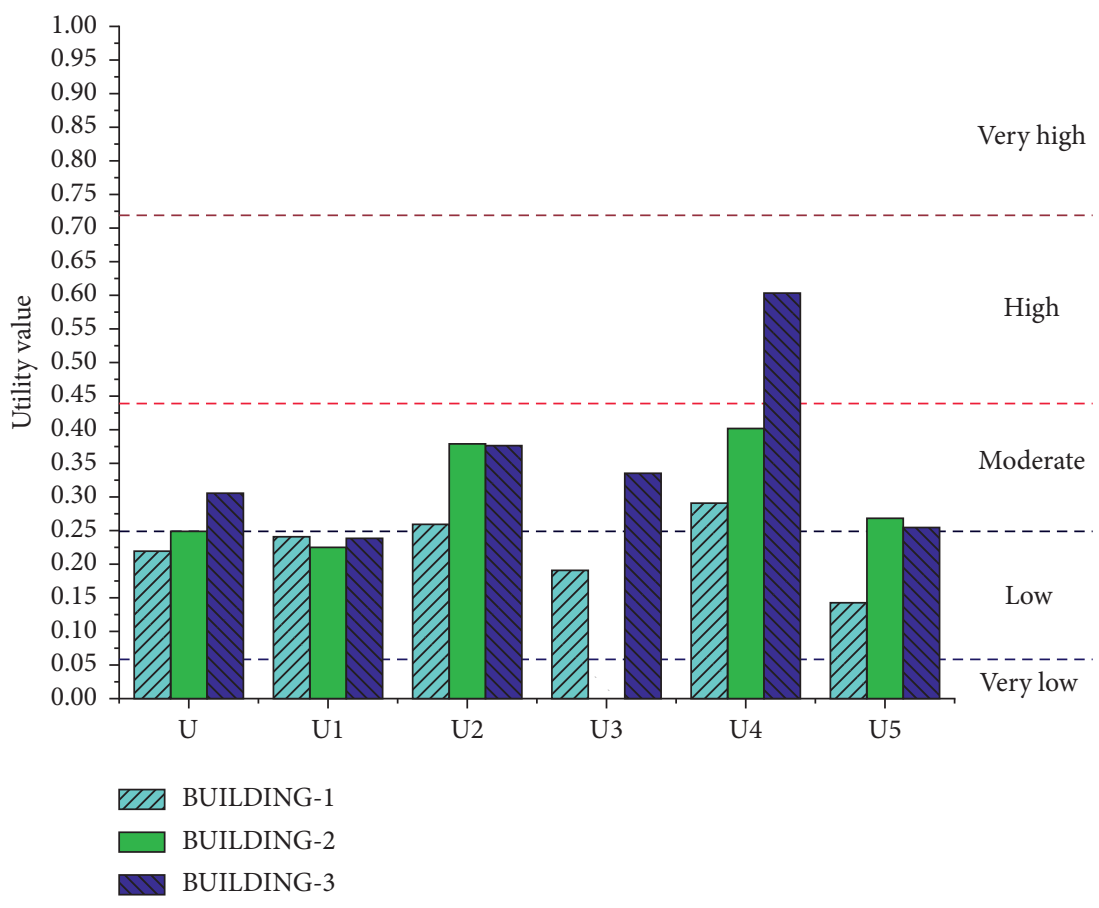

FIGURE 6: Utility values of the main factors.

\section{Conclusions}

This study proposes a novel model which combines evidence theory, fuzzy theory, and sensitivity analysis technique for assessing the building fire risk using inaccurate input data in order to optimize system operating efficiency by a standardized fuzzy linguistic term. This model is different from the traditional risk assessment model and characterized with flexible data acquisition capability and unified input and output modes. Therefore, it is easy to deal with the uncertainty of the fire risk problem in the complex system.

Furthermore, the model adopts a series of processes, such as weight calculation based on the FAHP, two-dimensional measurement of the fire risk based on triangular fuzzy numbers, construction of the belief structure, factor aggregation via the evidential reasoning algorithm, and assessment results using the expected utility method, to effectively address uncertainties of subjective estimation. In summary, the proposed model has the following advantages for fire risk analysis on the complex system: (1) this model presents a managerial view to analysts in a reasonable, reliable, and transparent way so that they can collaborate with experts' suggestion or on-site investigation to model complex systems under external uncertainties. (2) The model provides an effective tool for researchers to make full use of limited information to assess the fire risk of the whole system and improve its operational flexibility. (3) The model has strong flexibility, has high robustness, and is easy to program. It can be used as a computer tool for fire risk assessment of complex systems under high uncertainty.

This research proposes a quantitative fire risk assessment model which could provide building fire managers and researchers with flexible and transparent tools to effectively reduce the fire risk under the disturbance of fire risk uncertainty of the system. It should be noted that, in our study, the index scoring rules are mainly based on codes and standards, which lead to conservative results. Therefore, the acceptable level of fire risk based on performance-based codes needs to be determined in the future [46].

\section{Data Availability}

The data used to support the findings of this study are included within the article.

\section{Conflicts of Interest}

The authors declare that they have no conflicts of interest.

\section{Acknowledgments}

This work was supported by the National Natural Science Foundation of China (NSFC, 51704054 and 51874255), Key Technologies for Prevention and Control of Serious and Extraordinary Accidents of Ministry of Emergency Management (no. Chongqing-0001-2018AQ), the Natural Science Foundation of Chongqing (cstc2019jcyj-msxmX0462), and Scientific and Technological Research Program of Chongqing Municipal Education Commission (KJQN201801531 and KJQN201801519).

\section{References}

[1] J. M. Watts and J. R. Hall, "Introduction to fire risk analysis," in SFPE Handbook of Fire Protection Engineering, pp. 2817-2826, Springer, New York, NY, USA, 2016.

[2] J. Xin and C. Huang, "Fire risk analysis of residential buildings based on scenario clusters and its application in fire risk management," Fire Safety Journal, vol. 62, pp. 72-78, 2013. 
[3] G. Hadjisophocleous and Z. Fu, "Literature review of fire risk assessment methodologies," International Journal on Engineering Performance-Based Fire Codes, vol. 6, no. 1, pp. 28-45, 2004.

[4] D. Yung, "Cost-effective fire-safety upgrade options for a Canadian government office building," in Proceedings of the 1996 International Conference on Performance-Based Codes and Fire Safety Design Methods, Ottawa, Canada, 1996.

[5] J. J. H. P. Watts, "Systematic methods of evaluating fire safety: a review," Hazard Prevention, vol. 18, no. 2, pp. 24-27, 1981.

[6] N. Benichou, "FIERAsystem: a fire risk assessment tool to evaluate fire safety in industrial buildings and large spaces," Journal of Fire Protection Engineering, vol. 15, no. 3, pp. 145-172, 2005.

[7] Y. He and V. Beck, "A computer model for smoke spread in multi-storey buildings," in Proceedings of the 8th International Symposium on Transport Phenomena in Combustion, San Francisco, CA, USA, July 1995.

[8] V. Beck, "CESARE-RISK: a tool for performance-based fire engineering design," in Proceedings of 2nd International Conference on Performance-Based Codes and Fire Safety Design Methods, Maui, HI, USA, 1998.

[9] J. Fraser-Mitchell, "An object-oriented simulation (crisp 11) for fire risk assessment," Fire Safety Science, vol. 4, pp. 793804, 1994.

[10] M. N. Ibrahim, K. Abdul-Hamid, M. S. Ibrahim, A. MohdDin, R. M. Yunus, and M. R. Yahya, "The development of fire risk assessment method for heritage building," Procedia Engineering, vol. 20, pp. 317-324, 2011.

[11] S. M. Lo, "A fire safety assessment system for existing buildings," Fire Technology, vol. 35, no. 2, pp. 131-152, 1999.

[12] F. Liu, S. Zhao, M. Weng, and Y. Liu, "Fire risk assessment for large-scale commercial buildings based on structure entropy weight method," Safety Science, vol. 94, pp. 26-40, 2017.

[13] F. I. Khan, R. Sadiq, and T. Husain, "Risk-based process safety assessment and control measures design for offshore process facilities," Journal of Hazardous Materials, vol. 94, no. 1, pp. 1-36, 2002.

[14] M. Kalantarnia, F. Khan, and K. Hawboldt, "Dynamic risk assessment using failure assessment and Bayesian theory," Journal of Loss Prevention in the Process Industries, vol. 22, no. 5, pp. 600-606, 2009.

[15] A. John, D. Paraskevadakis, A. Bury, Z. Yang, R. Riahi, and J. Wang, "An integrated fuzzy risk assessment for seaport operations," Safety Science, vol. 68, pp. 180-194, 2014.

[16] National Fire Protection Association, NFPA 550: Guide to the Fire Safety Concepts Tree, National Fire Protection Association, Quincy, MA, USA, 2007.

[17] M. Omidvari, N. Mansouri, and J. Nouri, “A pattern of fire risk assessment and emergency management in educational center laboratories," Safety Science, vol. 73, pp. 34-42, 2015.

[18] G. Chen and X. Zhang, "Fuzzy-based methodology for performance assessment of emergency planning and its application," Journal of Loss Prevention in the Process Industries, vol. 22, no. 2, pp. 125-132, 2009.

[19] A. Grassi, R. Gamberini, C. Mora, and B. Rimini, "A fuzzy multi-attribute model for risk evaluation in workplaces," Safety Science, vol. 47, no. 5, pp. 707-716, 2009.

[20] M. Kobes, I. Helsloot, B. de Vries, and J. G. Post, "Building safety and human behaviour in fire: a literature review," Fire Safety Journal, vol. 45, no. 1, pp. 1-11, 2010.

[21] D.-Y. Chang, "Applications of the extent analysis method on fuzzy AHP," European Journal of Operational Research, vol. 95, no. 3, pp. 649-655, 1996.
[22] P. J. M. van Laarhoven and W. Pedrycz, "A fuzzy extension of Saaty's priority theory," Fuzzy Sets and Systems, vol. 11, no. 13, pp. 229-241, 1983.

[23] D.-Y. Chang, "Extent analysis and synthetic decision," $O p$ timization Techniques and Applications, vol. 1, no. 1, pp. 352-355, 1992.

[24] M. An, S. Huang, and C. J. Baker, "Railway risk assessment-the fuzzy reasoning approach and fuzzy analytic hierarchy process approaches: a case study of shunting at Waterloo depot," Proceedings of the Institution of Mechanical Engineers, Part F: Journal of Rail and Rapid Transit, vol. 221, no. 3, pp. 365-383, 2007.

[25] J. J. Buckley, "Fuzzy hierarchical analysis," Fuzzy Sets and Systems, vol. 17, no. 3, pp. 233-247, 1985.

[26] Y. Li and X. Liao, "Decision support for risk analysis on dynamic alliance," Decision Support Systems, vol. 42, no. 4, pp. 2043-2059, 2007.

[27] D. J. C. E. P. Simon, "Fuzzy sets and fuzzy logic," Theory and Applications, vol. 9, no. 4, pp. 1332-1333, 1996.

[28] E. W. T. Ngai and F. K. T. Wat, "Fuzzy decision support system for risk analysis in e-commerce development," Decision Support Systems, vol. 40, no. 2, pp. 235-255, 2005.

[29] R. Sadiq, E. Saint-Martin, and Y. Kleiner, "Predicting risk of water quality failures in distribution networks under uncertainties using fault-tree analysis," Urban Water Journal, vol. 5, no. 4, pp. 287-304, 2008.

[30] L. Krishnasamy, F. Khan, and M. Haddara, "Development of a risk-based maintenance (RBM) strategy for a power-generating plant," Journal of Loss Prevention in the Process Industries, vol. 18, no. 2, pp. 69-81, 2005.

[31] G. Shafer, A Mathematical Theory of Evidence, Vol. 42, Princeton University Press, Princeton, NJ, USA, 1976.

[32] R. L. D. Mantaras, Approximate Reasoning Models, Prentice Hall PTR, Upper Saddle River, NJ, USA, 1990.

[33] R. R. Yager, "On the determination of strength of belief for decision support under uncertainty-part II: fusing strengths of belief," Fuzzy Sets and Systems, vol. 142, no. 1, pp. 129-142, 2004.

[34] J.-B. Yang and D.-L. Xu, "On the evidential reasoning algorithm for multiple attribute decision analysis under uncertainty," IEEE Transactions on Systems, Man, and Cybernetics-Part A: Systems and Humans, vol. 32, no. 3, pp. 289-304, 2002.

[35] Y. Jian-Bo and M. G. Singh, "An evidential reasoning approach for multiple-attribute decision making with uncertainty," IEEE Transactions on Systems, Man, and Cybernetics, vol. 24, no. 1, pp. 1-18, 1994.

[36] J.-B. Yang, "Rule and utility based evidential reasoning approach for multiattribute decision analysis under uncertainties," European Journal of Operational Research, vol. 131, no. 1, pp. 31-61, 2001.

[37] Y.-M. Wang, J.-B. Yang, and D.-L. Xu, "Environmental impact assessment using the evidential reasoning approach," European Journal of Operational Research, vol. 174, no. 3, pp. 1885-1913, 2006.

[38] D.-L. Xu and J.-B. Yang, "Intelligent decision system for selfassessment," Journal of Multi-Criteria Decision Analysis, vol. 12, no. 1, pp. 43-60, 2003.

[39] S. Contini, S. Scheer, and M. Wilikens, "Sensitivity analysis for system design improvement," in Proceedings International Conference on Dependable Systems and Networks, 2000, New York, NY, USA, June 2000.

[40] X. Wu, Residential Fire Risk Assessment and Control Strategies, Central South University, Changsha, China, 2014. 
[41] J. Wang, J. B. Yang, and P. Sen, "Safety analysis and synthesis using fuzzy sets and evidential reasoning," Reliability Engineering \& System Safety, vol. 47, no. 2, pp. 103-118, 1995.

[42] GB50016-2014, Code for Fire Protection Design of Buildings, China Planning Press, Beijing, China, 2007.

[43] GB 50222-2017, Code for Fire Prevention in Design of Interior Decoration of Buildings, Ministry of Construction of the People's Republic of China, Beijing, China, 2001.

[44] P. H. Thomas, "Design guide: structure fire safety CIB W14 workshop report," Fire Safety Journal, vol. 10, no. 2, pp. 77-137, 1986.

[45] L. Zhang, High-Rise Building Fire Risk Evaluation and Intelligent Alarm System Research, Beijing Institute of Technology, Beijing, China, 2015.

[46] V. Kodur, P. Kumar, and M. M. Rafi, "Fire hazard in buildings: review, assessment and strategies for improving fire safety," PSU Research Review, vol. 4, no. 1, pp. 1-23, 2019. 